Volume 9, No.5, September - October 2020

International Journal of Advanced Trends in Computer Science and Engineering

Available Online at http://www.warse.org/IJATCSE/static/pdf/file/ijatcse03952020.pdf

https://doi.org/10.30534/ijatcse/2020/03952020

\title{
A Generalized SVPWM Scheme for Multilevel Inverters with Fixed Computational Time
}

\author{
Krishna Chaitanya $\mathrm{M}^{1}$, Sambasiva Rao $\mathrm{G}^{2}$ and Amarendra Matsa ${ }^{3}$ \\ ${ }^{1}$ Research Scholar, Acharya Nagarjuna University, Guntur, mleela.venkata@ gmail.com \\ ${ }^{2}$ Professor, RVR \& JC College of Engineering, Guntur \\ ${ }^{3}$ Associate Professor, Mizoram University ( A central university), Aizawl.
}

\begin{abstract}
This research article proposes a generalized SVPWM method for multilevel inverters with fixed computational time. In this proposed modulation process the reference vector is located triangle is identified very quickly by using $120^{\circ}$ co-ordinate system in first sector. The switching states of the remaining sectors are determined by using the relationship with the first sector. The proposed modulation method procedure is invariant with the voltage level of the multilevel inverter and this method need not to use any look-up table's information. Therefore the computational time and data storage space is very less and very easy to implement in real time with cost-effective. The capacity of the generalized SVPWM method is verified by MATLAB/SIMULINK.
\end{abstract}

Key words: Multi-level Inverters; Cascaded H-Bridge Inverters; SVPWM.

\section{INTRODUCTION}

The applications of Multi-level inverters are widely spread in all industries due to its advantages like lesser THD, reduction in switch capacity, lower rate change of voltage and lower operating switching frequency. The basic classification of multilevel inverter topologies are Diode Clammped inverter, Flying capacitor type inverter and Cascaded H-Bridge Multilevel inverter. Among these Cascaded H-Bridge inverter having flexibility with modular option and having requirement of lesser power electronics components.

There are different modulation methods are used for Multilevel inverters such as phase shifted PWM, Level shifted PWM and Space Vector PWM (SVPWM). Among all comparatively SVPWM is more convenient due to be redundancy in the switching sequence selection and possible of effective implementation using Digital signal Processors. However, with conventional SVPWM [1-10] there are generally $6(n-1)^{2}$ triangles $n^{3}$ switching states in the space vector diagram of 3-phase n-level inverter. In this modulation method exact location of the triangle and proper switching states is to be estimated. The real time needed to do these operations decides the performance of the inverter.

In [11] author had proposed a SVPWM method that the NTV are determined and their duty ratio of the vectors are found through $60^{\circ}$ co-ordinate system. But, this system more complicated than proposed $120^{\circ}$ co-ordinate system. Thesolution to get quick calculation of duty ratio of the NTV is given in [12] but, this method is implemented with look-up table's information. References [13, 14] proposed a SVPWM which depends on iterative method to find NTV but, the computational time increases with voltage level. In [15-17] authors had proposed the decomposition method to solve the SVD of the different multilevel inverters. This method is also uses the look-up tables to find the switching functions.

This article proposes a generalized SVPWM that has fixed computational time to any voltage level multilevel inverters. In the proposed SVPWM the identification of nearest three vectors (NTV) are done very quickly with $120^{\circ}$ coordinated system. There after the duty ratios of NTV and switching sequence is computed as simple two level inverter SVPWM methods. The computation (execution) time and memory required to the proposed SVPWM is not varied which is fixed to any level multilevel inverter.

\section{DESCRIPTION OF THE PROPOSED GENERALIZED SVPWM METHOD}

The reference voltage vector of general multilevel inverterVref is generated by

$$
V_{\text {ref }}=E\left(S_{0}+S_{1} e^{j \frac{3 \Pi}{3}}+S_{2} e^{j \frac{4 \Pi}{3}}\right)
$$

Where $\mathrm{E}$ is the Voltage source of basic module of the inverter and $S_{0}, S_{1}$ and $S_{2}$ are the switching states of three phases respectively.

A. Determination of Vref locus triangles and finding nearby three vectors of the triangle

The proposed generalized SVPWM scheme process consists of general procedure of any level of inverter with fixed computational time. Fig.1shows the four level SVD diagram is used for analyzing the proposed scheme. The SVD diagram is separated into six sectors of $60^{\circ}$ each. The reference voltage vector sector $\operatorname{position}(S=1,2 \ldots 6)$ is determined by

$$
S=\text { integer }\left(\frac{3 \theta}{\pi}\right)+1
$$

The general principle of SVPWM contains conversion from stationary axis (abc) to $\alpha \beta$ axis system. But, in this conversion process it is not possible to utilize the symmetry of the SVD effectively to simplify computation process. Fig. 2 shows the SVD of the sector 1 in $\alpha \beta$ plane, which indicted as vertex points are not a integer values. Whereas in SVD of the sector 1 in $120^{\circ}$ coordinate system shown in Figure. 3 the vertex coordinate are points are exact integer values. This makes system computation procedure more convenient than $\alpha \beta$ axis system. 


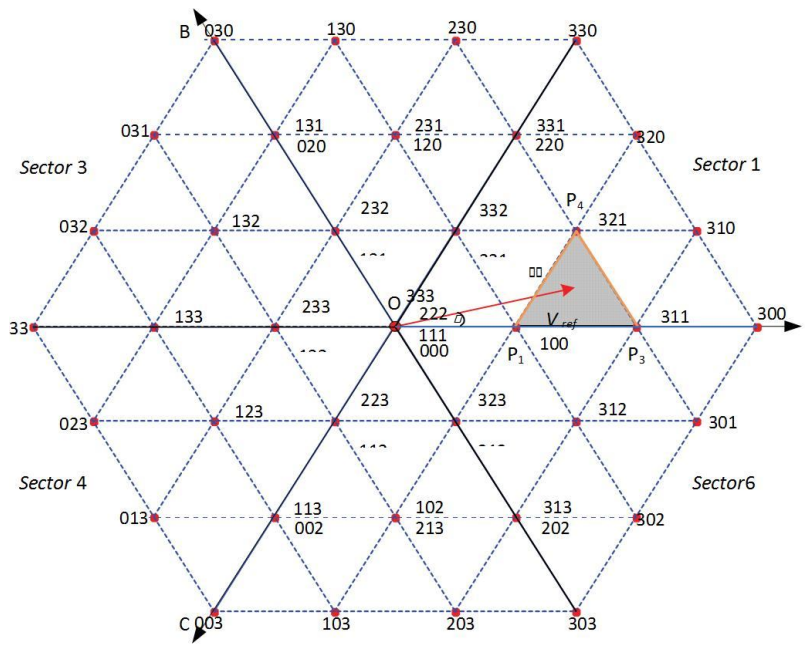

Figure 1: SVD diagram for four-level

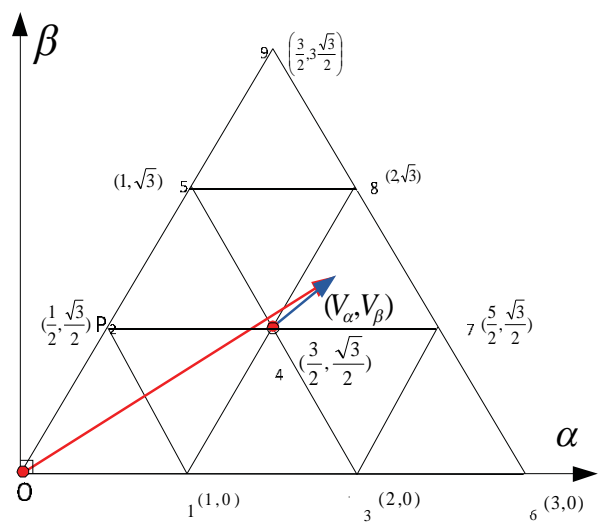

Figure 2: SVD of First sector in $\alpha-\beta$ axis system

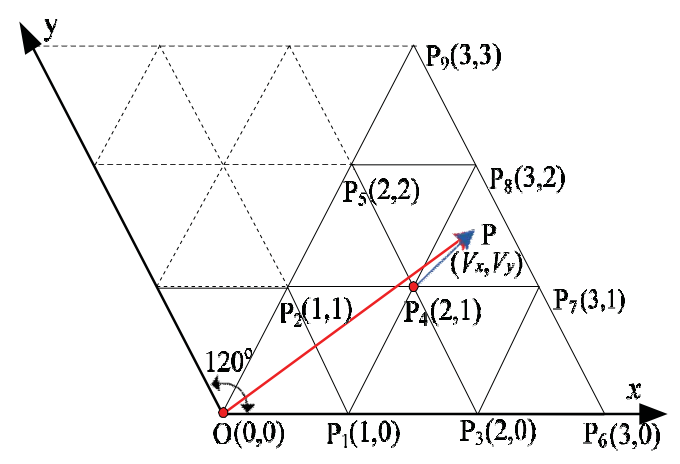

Figure 3: SVD of First sector $120^{\circ}$ axis system

The general principle of SVPWM contains conversion from stationary axis (abc) to $\alpha \beta$ axis system. But, in this conversion process it is not possible to utilize the symmetry of the SVD effectively to simplify computation process. Figure. 2 shows the SVD of the sector 1 in $\alpha \beta$ plane, which indicted as vertex points are not a integer values. Whereas in SVD of the sector 1 in $120^{\circ}$ coordinate system shown in Figure. 3 the vertex coordinate are points are exact integer values. This makes system computation procedure more convenient than $\alpha \beta$ axis system.

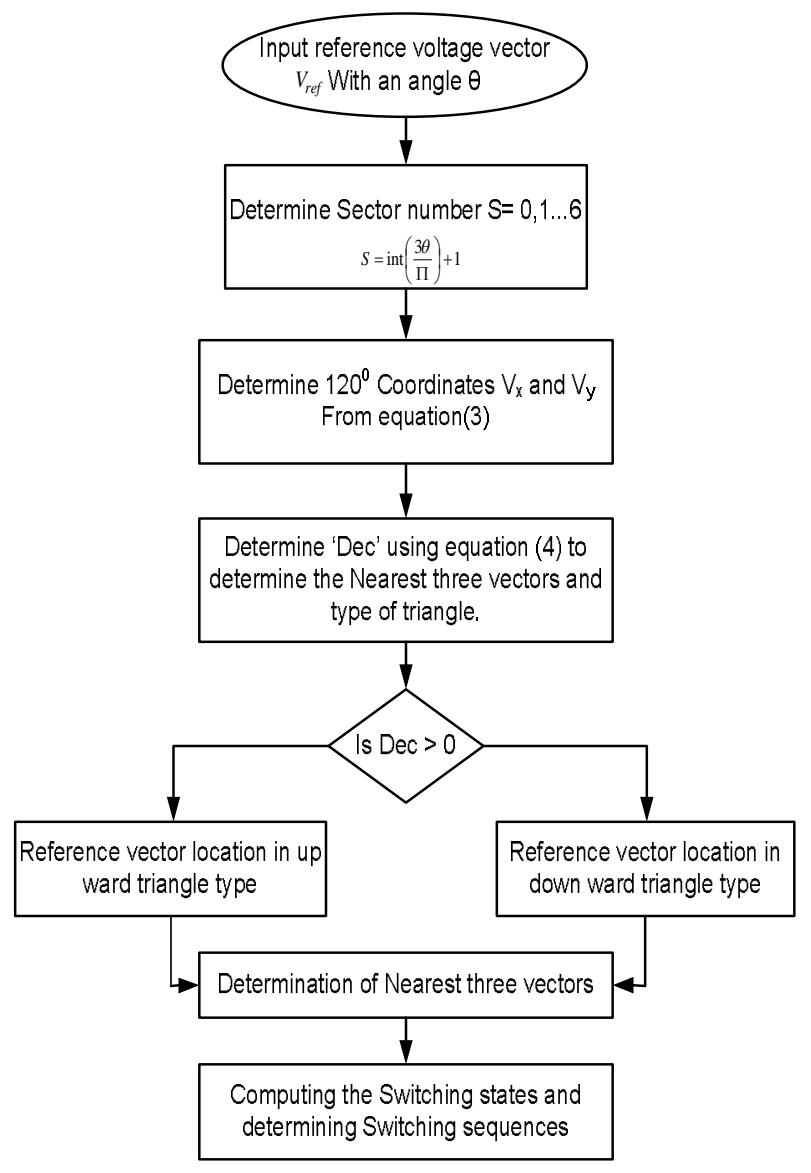

Figure 4: Proposed SVPWM flow chart

The $\mathrm{V}_{\text {ref }}$ voltage vector tip can be placed in any nine triangles of sector 1 . The $120^{\circ}$ coordinated system transformed vertex points are given by

$$
\begin{aligned}
& V_{x}=V_{\propto}+\frac{V_{\beta}}{\sqrt{3}}, V_{y}=\frac{2 V_{\beta}}{\sqrt{3}} \\
& k_{1}=\operatorname{integer}\left(V_{x}\right), k_{2}=\operatorname{integer}\left(V_{y}\right)
\end{aligned}
$$

Where $K_{1}$ and $K_{2}$ are the rounded integer values of $V_{x}$ and $V_{y}$ respectively.

After finding the coordinates of $\mathrm{V}_{\mathrm{x}}$ and $\mathrm{V}_{\mathrm{y}}$ the origin point ' $\mathrm{O}$ ' is shifted to new base point near to tip of the 'OP' vector. After shifting there is an intricacy to find specific triangle typedue to the new reference vector may touch in any basic triangles has common base reference point. It is observed in Figure 2 is point ' $\mathrm{P}_{4}$ ' is common base point to triangles $\mathrm{P}_{7} \mathrm{P}_{4} \mathrm{P}_{8}$ and $\mathrm{P}_{4} \mathrm{P}_{8} \mathrm{P}_{5}$. The specific modulation triangle is determined from the factor 'dec' as follows

$$
\operatorname{dec}=\left(V_{x}-V_{y}\right)-\left(k_{1}-k_{2}\right)
$$

If $\mathrm{dec} \geq 0$, the position of the new reference vector is present on the upward triangle whereas if $\operatorname{dec}<0$, the position of the new base reference vector there on the downward triangle. After finding the exact modulation triangle type the next step is to determine the coordinates of reaming two points. The NTV are used to implement general two-level PWM method. 


\section{B. Calculation of Duty ratio of the NTV}

The duty ratio of each NTV are to find the position of the new reference vector. The Voltage-Second average law of reference vector of identified triangle type I shown in Figure 3 is given as

$$
(O P) T=\left(O P_{4}\right) t_{o}+\left(O P_{7}\right) t_{1}+\left(O P_{8}\right) t_{2}
$$

Then $t_{1}=\left(V_{x}-V_{y}+k_{1}-k_{2}\right) T$

$$
t_{2}=\left(V_{x}-k_{2}\right) T
$$

\section{SIMULATION RESULTS}

Simulation results are analyzed with MATLAB/Simulink to authenticate the proposed generalized SVPWM method. The simulation system parameters are considered as $2 \mathrm{kHz}$ switching frequency, $50 \mathrm{~Hz}$ fundamental frequency, the DC input voltage is $100 \mathrm{~V}$ and modulation index $\mathrm{Ma}=1.0$.
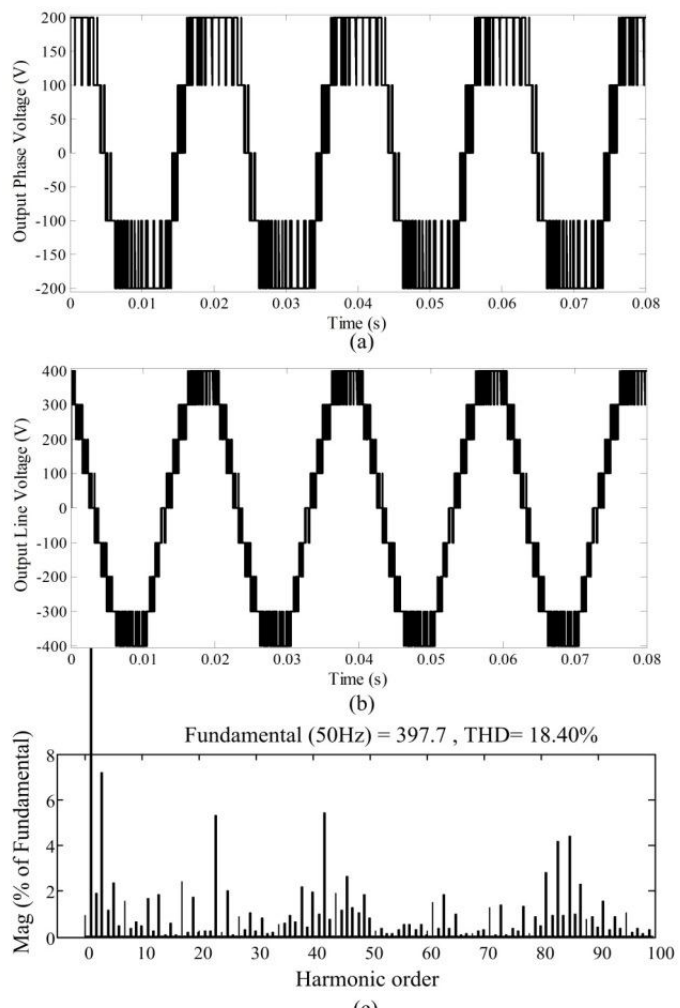

(c)

Figure 5: 5-level H-Bridge output (a) Phase Voltage (b) Line Voltage (c) THD

Fig. 5 shows the output waveforms of a five level cascaded H-bridge inverter with proposed $120^{\circ}$ coordinate system technique. The obtained results are extracted with resistive loading conditions. It is observed from the results waveform that the fundamental voltage is $397.7 \mathrm{~V}$ and the THD is 18.40 $\%$. The computational time of the simulation to the proposed SVPWM method is noted as $25 \mu \mathrm{CPU}$ time which is same for seven, thirteen and twenty one level inverters with the proposed method shown in Fig. 6, Fig. 7 and Fig. 8 respectively.
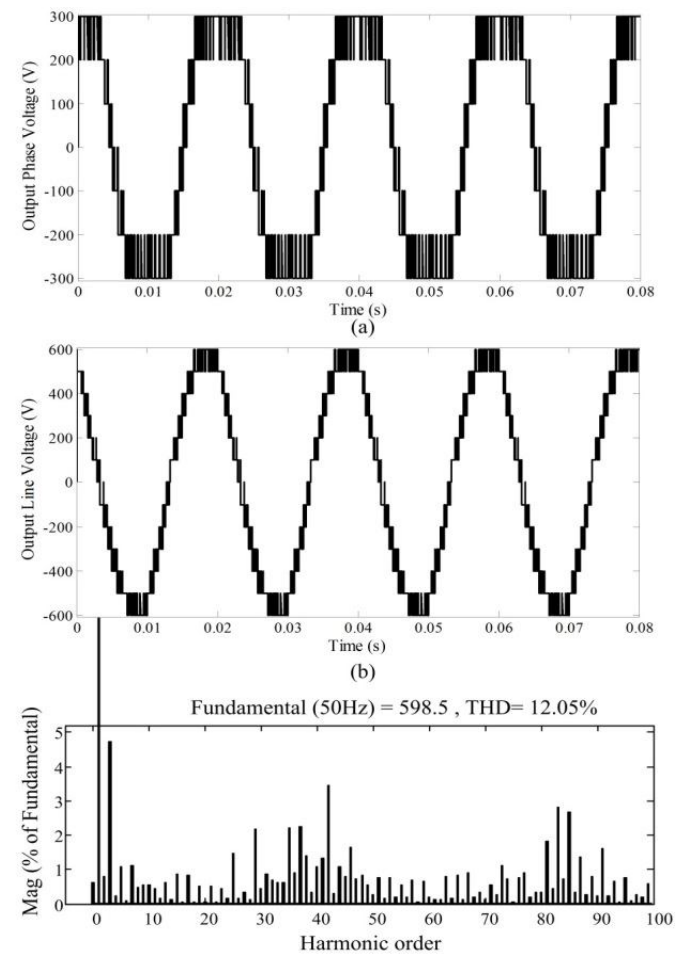

(c)

Figure 6: 7-level H-Bridge output (a) Phase Voltage (b) Line Voltage (c) THD.
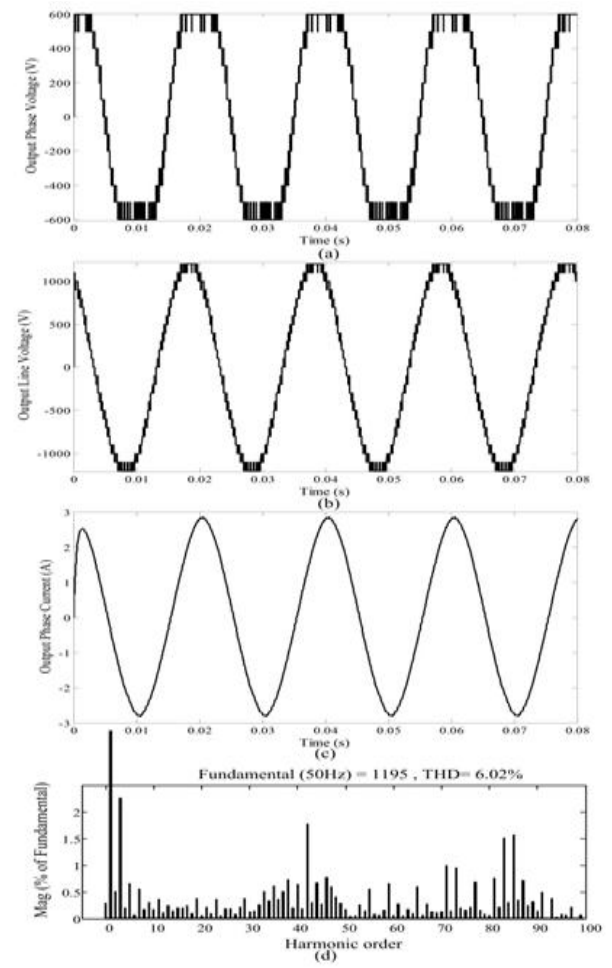

Figure 7: 13- level output (a) Phase Voltage (b) Line Voltage (c) Phase current (d) THD. 

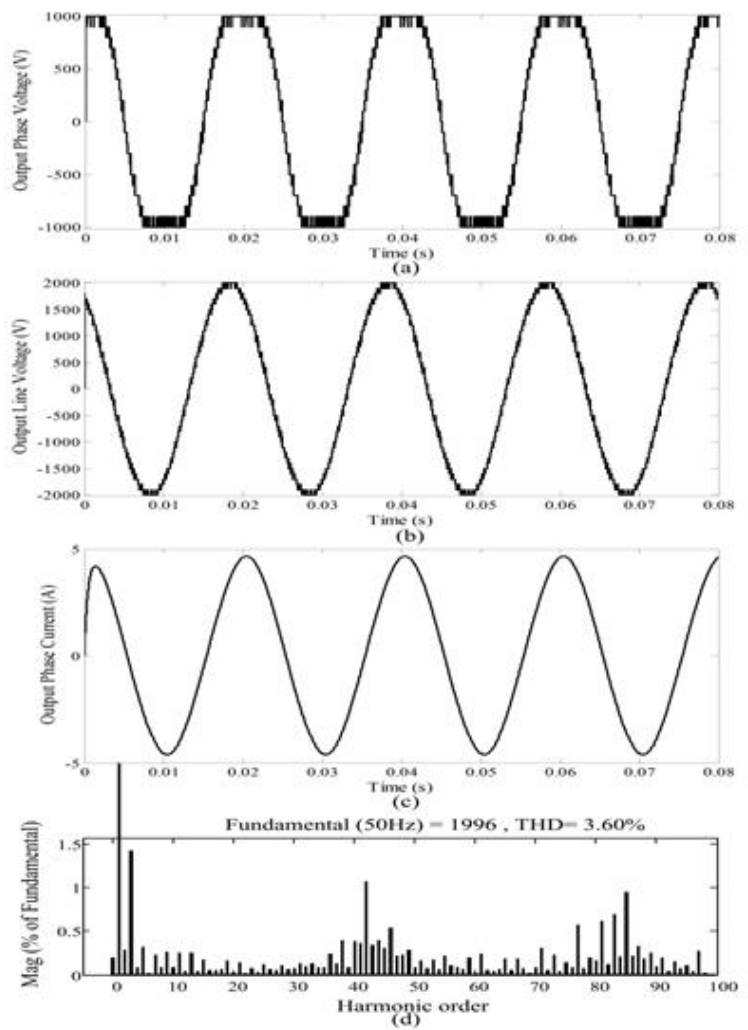

Figure 8: 21- level output (a) Phase Voltage (b) Line Voltage (c) Phase current (d) THD.

\section{CONCLUSION}

In the proposed generalized SVPWM method the type of the modulation triangle is and NTV are located very easily based on $120^{\circ}$ coordinate method transformation. Then the duty ratios and switching combinations of NTV are computed without insertion of any look-up table data. This will creates the fixed computation time as well as less memory requirement to processor leads to the improvement in the computational time compared to other methods. Therefore with the above advantages the proposed SVPWM method is cost effective to any level of inverters.

\section{REFERENCES}

[1]. A. Nabae, I. Takahashi, and H. Akagi, "A new neutral-point-clamped PWM inverter," IEEE Trans. Ind. App., vol. IA-17, no. 5, Sept. 1981, pp. 518-523.

[2]. G. Walker, and G. Ledwich, "Bandwidth considerations for multilevel converters," IEEE Trans., Power Electron., vol. 14. no. 1, Jan. 1999, pp. 74-81.

[3]. J. S. Lai and F. Z. Peng, "Multilevel converters - A new breed of power converters," IEEE Trans. Ind. App., vol. 32, no. 3, May/June 1996, pp. 509-517.

[4]. L. Tolbert, F. Z. Peng, and T. Habetler, "Multilevel converters for large electric drives," IEEE Trans. Ind. Applicat., vol. 35, no. 1, Jan./Feb. 1999, pp. 36-44.

[5]. J. Rodriguez, J. S Lai, and F. Z. Peng, "Multilevel inverters: a survey of topologies, controls, and applications," IEEE Trans. Ind. Electron., vol. 49, no. 4, Aug. 2002, pp. 724- 738.

[6]. M. Hiller, D. Krug, R. Sommer and S. Rohner, "A new highly modular medium voltage converter topology for industrial drive applications," 2009 13th European
Conference on Power Electronics and Applications, Barcelona, 2009, pp. 1-10.

[7]. L. G. Franquelo, J. Rodriguez, J. I. Leon, S. Kouro, R. Portillo, and M. A. M. Prats, "The age of multilevel converters arrives," IEEE Ind.Electron. Mag., vol. 2, no. 2, Jun. 2008, pp. 28-39.

[8]. A. Edpuganti and A. K. Rathore, "A Survey of Low Switching Frequency Modulation Techniques for Medium-Voltage Multilevel Converters," in IEEE Transactions on Industry Applications, vol. 51, no. 5, Sept.-Oct. 2015, pp. 4212-4228.

[9]. J. Rodriguez et al., "Multilevel Converters: An Enabling Technology for High-Power Applications," in Proceedings of the IEEE, vol. 97, no. 11, Nov. 2009, pp. 1786-1817.

[10]. J. Holtz and N. Oikonomou, "Neutral point potential balancing algorithm at low modulation index for three-level inverter medium voltage drives," Fourtieth IAS Annual Meeting. Conference Record of the 2005 Industry Applications Conference, 2005., Kowloon, Hong Kong, 2005, pp. 1246-1252

[11].N Celanovic, Boroyevich, "A fast space-vector modulation algorithm for multilevel three-phase converters," IEEE Transations on Industrial Applications, vol. IA-37, no. 2, Mar./Apr. 2001, pp. 637-641.

[12].A. K. GuptaandA. M. Khambadkone,"A space vector PWM scheme form ultilevel inverters based on two-level space vector PWM,"IEEE Transations Industrial Applications, vol. 53, no. 5, Oct. 2006, pp. 1631-1639.

[13].M. A. S. Aneesh, A. Gopinath, and M. R. Baiju, "A simple space vector PWM generation scheme for any general n-level inverter," IEEE Transationson Industrial Applications, vol. 56, no. 5, May2009, pp. 1649-1656.

[14]. Y. Deng, K. H. Teo, C. Duan, T. G. Habetler, and R. G. Harley, "A

fast andgeneralizedspacevectormodulationschemeformultilev elinverters," IEEE Transactions on Power Electron.,vol. 29,no. 10,Oct. 2014, pp. 5204-5217.

[15]. Amarendra Matsa, Irfan Ahmed, and Madhuri A. Chaudhari, "Optimized Space Vector Pulse-width Modulation Technique for a Five-level Cascaded $\mathrm{H}$ Bridge Inverter,"Journal of power electronics, vol.14, no.5, Sep. 2014, pp. 937-945.

[16].I. Ahmed; V. Borghate; Amarendra Matsa; P. Meshram; H. Suryawanshi; M. A. Chaudhari, "Simplified Space Vector Modulation Techniques for Multilevel Inverters," in IEEE Transations on Power Electronics, Doi:10.1109/TPEL.2016.2520078.

[17].Amarendra Matsa, MA Chaudhari, HM Suryawanshi “ Modified Synchronous Vector Control Design of Multilevel Inverters for AC Grid Applications", Electric Power Components and Systems, vol.45, no.8, Mar. 2017, pp. 881-893. 